\title{
Tânia Carvalhal e as trilhas do comparatismo: esboço de um perfil
}

\author{
EduARDo F. COUTINHO \\ Universidade Federal do Rio de Janeiro
}

RESUMO: O TEXTO ESTABELECE UM PERFIL DA CRITICA LITERÁRIA E TEÓRICA DA LITERATURA COMPARADA TANIA FRANCO CARVALHAL, NA PERSPECTIVA DE UM DE SEUS COLABORADORES MAIS PRÓXIMOS, ENFATIZANDO A RELEVÂNCIA DE SEU TRABALHO PIONEFRO COM A LITERATURA COMPARADA NO BRASIL.

ABSTRACT: THIS ARTICLE TRACES A PROFILE OF THE BRAZILIAN LITERARY CRITIC AND COMPARATIVE LITERATURE THEORIST TANIA FRANCO CARVALHAL, ACCORDING TO ONE OF HER CLOSEST CO-WORKERS, STRESSING HER RELEVANT AND PIONEERING CONTRIBUTION TO THE FIELD OF COMPARATIVE LITERATURE IN BRAZIL.

PALAVRAS-CHAVE: COMPARATISMO - TEORIA LITERÁRIA - ABRALIC - TANIA FRANCO CARVALHAL

KEY-WORDS: COMPARATIVE LITERATURE - LITERARY THEORY - ABRALIC - TANIA FRANCO CARVALHAL 
alar de Tania Carvalhal significa muito mais que a mera apologia à incansável pesquisadora, à crítica sensível do fenômeno literário, à escritora meticulosa, perseguidora do mot juste, ou ainda à empreendedora de foros de debates e circuitos de investigação que contribuíram enormemente para a divulgação da literatura comparada. Falar de seu trabalho, para mim, constitui um registro mais amplo: é a história de um diálogo, iniciado em Paris, nos idos de 1985, no seio da Associação Internacional de Literatura Comparada, a AILC/ICLA, e que não iria nunca arrefecer; ao contrário, continuaria a dar frutos mesmo agora, após o seu triste falecimento, no dia 10 de setembro de 2006, por meio dos projetos que implantamos de desenvolvimento do comparatismo no Brasil.

Formada em Letras, com um mestrado em Literatura Brasileira e um doutorado em Teoria Literária e Literatura Comparada pela Universidade de São Paulo, Tania Carvalhal iniciou sua carreira muito cedo, como professora de Literatura Francesa na Universidade Federal do Rio Grande do Sul, em que veio a se tornar, depois de um brilhante percurso, Professora Emérita (2005). Entre 1971 e 1972, ela passou um ano em Paris, onde estudou com Roland Barthes, Jean-Claude Chevalier e George Raillard, entre outros. De retorno a Porto Alegre, começou a lecionar Teoria Literária e em seguida Literatura Comparada, mas sem deixar de lado, em momento algum, seu interesse pelas literaturas francesa e brasileira. Suas primeiras publicações foram sobre autores como Molière, Claudel, Mauriac, Ionesco, Beckett, Adamov, e os brasileiros Augusto Meyer (objeto de suas teses de mestrado e doutorado) e Mario Quintana. E seus primeiros cursos foram voltados para as relações entre as literaturas francesa e brasileira.

Os textos de Tania Carvalhal constituem uma clara evidência de seu perfil como verdadeira comparatista, podendo ser agrupados em duas grandes vertentes: estudos sobre a natureza ou a história da Literatura Comparada e das relações da disciplina com os discursos da teoria e da crítica literárias, e estudos comparativos de autores, obras e movimentos, bem como de textos literários e outros produtos de expressão artística ou cultural. No primeiro caso, destaque-se o livro Literatura Comparada (1986), estudo introdutório da maior importância sobre o assunto, e Literatura Comparada: textos fundadores (1994), organizado conjuntamente comigo, e que constitui a primeira antologia de textos traduzidos para o português sobre a configuração e consoli- 
dação da disciplina no Ocidente. No segundo caso, merecem menção, entre outros, A evidência mascarada (1984), obra que constitui um marco na fortuna crítica de Augusto Meyer, e O próprio e o alheio (2003), coleção de ensaios da mais alta categoria e mais fina sensibilidade crítica, toda voltada para questões mais recentes dos estudos de Literatura Comparada.

Os ensaios de Tania Carvalhal tratam de grande variedade de assuntos, constituindo a maior evidência de sua erudição e talento especiais, e são escritos com esmero, em estilo claro e preciso. Tania inscreve-se na linha dos ensaístas para quem os meios de expressão revelam-se tão importantes quanto o que ela quer transmitir, e seus textos são reescritos muitas vezes, até chegarem a sua forma definitiva. O resultado é um ensaio poético, em que se aliam plasticidade e solidez, e que fazem da atividade do leitor uma tarefa prazerosa. A imaginação e a criatividade estão sempre presentes em seu labor, mesmo naqueles textos mais marcadamente teóricos, e sua reflexão se desenvolve de maneira que fascina o leitor.

$\mathrm{Na}$ esfera da Literatura Comparada, Tania sempre expressou grande preocupação com a dialética entre o local e o universal, e se dedicou amplamente ao estudo da tradição brasileira, ou, mais especificamente, da forte tradição regionalista de seu estado natal, o Rio Grande do Sul. Ela foi, por algum tempo, diretora do Instituto Estadual do Livro, em Porto Alegre, e publicou um número expressivo de edições críticas das obras de autores locais, com sólidas notas introdutórias e estudos críticos que hoje constituem itens indispensáveis em suas bibliografias passivas. Nessa mesma esteira, ela demonstrou também acentuada preocupação com o estudo das relações literárias entre o Brasil e os demais países latino-americanos, tendo produzido diversos textos nessa seara. Movida pelo interesse crescente que os estudos latino-americanos vinham despertando no Brasil e pelo parentesco existente entre a produção literária e cultural brasileira e a hispano-americana, Tania se associou aos pesquisadores que já vinham desenvolvendo essa área de estudos no Brasil - e prestou-lhes valiosa contribuição ao aproximá-los de seus colegas hispano-americanos, particularmente os do Cone Sul, por meio da organização de eventos marcados por debates instigantes.

Como professora de Literatura, Tania Carvalhal se destacou não só em sua universidade de origem, a UFRGS, como também nas demais instituições, tanto do Brasil quanto do exterior, em que atuou como professora 
visitante, ministrando cursos intensivos: a Universidade de Victoria (Canadá), a Universidade de Indiana (Estados Unidos), a Universidade de Paris IV - Sorbonne, as Universidades de Córdoba e Salta (Argentina), a Universidade de Barcelona e a Universidade de São Paulo. Na Universidade Federal do Rio Grande do Sul, pela sua intensa atividade docente, que incluía um amplo espectro de disciplinas, desde as Literaturas Francesa e Brasileira até a Teoria Literária e a Literatura Comparada, os cargos importantes que ocupou e a orientação de um número expressivo de teses e dissertações, ela deixou escola, constituída por um grupo altamente qualificado de professores que vêm hoje, com grande dedicação e entusiasmo, dando continuidade ao seu trabalho e conquistando um espaço cada vez maior no meio acadêmico do país.

Foi com seu espírito pioneiro e de firme determinação que Tania levou a cabo, junto comigo e alguns outros comparatistas aventureiros, a tarefa de fundar a Associação Brasileira de Literatura Comparada (ABRALIC). A idéia surgiu em 1985, em Paris, durante o XI Congresso da Associação Internacional de Literatura Comparada (AILC/ICLA), realizado na Sorbonne Nouvelle. Lá, em meio a intensos debates sobre todos os aspectos relacionados à disciplina, desde questões mais específicas pertinentes à Narratologia, à Semiologia e à Estética da Recepção, à época muito em voga, até uma ampla discussão sobre a tradução, a oposição entre o oral e o escrito e os diálogos de culturas, Tania propôs-me de súbito: por que não fundamos uma associação nacional de Literatura Comparada, como as que temos visto aqui representadas, e a vinculamos à AILC/ICLA? Do susto inicial, passei à reflexão, e brindamos a futura realização na recepção de encerramento do congresso, junto a outras duas participantes brasileiras, em tarde memorável, sobre as águas do Sena.

A idéia, felizmente, não ficou em projeto. O objetivo comum - o desejo de propiciar, por meio de um intercâmbio mais dinâmico com os demais pólos de estudos da disciplina, um desenvolvimento verdadeiramente eficaz do comparatismo no Brasil - e a confluência de áreas de atuação distintas, mas complementares - Tania transitava sobretudo pelas literaturas francesa e brasileira e eu pela brasileira e a hispano-americana, além da norte-americana, que lecionara durante um tempo - foram responsáveis pelo resto da aproximação. De regresso ao Brasil, mantivemos contato e, após ampliarmos o grupo fundador com a inclusão de outros pesquisadores da matéria, 
fundamos, a 9 de setembro de 1986, na Universidade Federal do Rio Grande do Sul, em Porto Alegre, a Associação Brasileira de Literatura Comparada, a ABRALIC. E Tania, sua primeira presidente, organizou, dois anos depois, o primeiro congresso da Associação, também na UFRGS, ao qual estiveram presentes, além de um número expressivo de intelectuais brasileiros, quase todos os principais integrantes da diretoria, à época, da AILC/ICLA.

As dificuldades na fase de implantação da ABRALIC foram muitas, evidentemente, mas os esforços foram compensados. Hoje a associação, que conta com mais de dois mil sócios, entre professores e pesquisadores de literatura, é o principal órgão de estudos literários comparativos no Brasil, e o seu raio de atuação já alcançou amplas esferas, tendo constituído, inclusive, estímulo para a criação de novos cursos de pós-graduação na área. Suas atividades nessas já duas décadas de existência foram incontáveis, destacando-se, sobretudo, a realização de dez congressos internacionais de grande repercussão, seguidos da publicação dos respectivos anais, que constituem itens indispensáveis na bibliografia do comparatismo no Brasil. Além disso, há que se acrescentar a realização de diversos colóquios e seminários e a criação de dois veículos sumamente importantes de divulgação: o boletim informativo Contraponto e a Revista Brasileira de Literatura Comparada, de qualidade reconhecida.

Mas o dinamismo e o entusiasmo de Tania não se restringiram à criação da ABRALIC. Junto à AILC, em que, aliás, desenvolvemos ampla parceria, sua atividade foi infatigável, tendo sido primeiramente membro do conselho executivo durante duas gestões, em seguida vice-presidente, e finalmente presidente - a primeira presidente latino-americana dessa associação de já mais de cinqüenta anos -, cargo que exerceu até o seu falecimento. E entre suas atividades no âmbito da Associação, cabe destacar a fundação do Comitê de Estudos Latino-Americanos, sua participação na criação de outras associações nacionais - a argentina, a uruguaia e mais recentemente a peruana -, a organização de colóquios e simpósios, muitos deles na velha sede da UFRGS, com a presença sempre expressiva da AILC e de figuras representativas do meio intelectual brasileiro e hispano-americano, e a colaboração constante que sempre prestou por meio de publicações.

É como eminente professora, devotada à formação e à projeção de seus alunos no meio acadêmico, como escritora, autora de diversos livros que 
prestaram inestimável contribuição para o desenvolvimento do comparatismo no Brasil e organizadora de um grande número de outros - em especial sobre autores de sua terra, o Rio Grande do Sul -, como pensadora, que soube muito bem dosar a prática acadêmica e a vivência no meio intelectual e artístico dentro e fora de seu país, e como empreendedora, que soube tornar concretas e manter com pulso firme muitas de suas idealizações, que a homenageamos com este texto. Mas é sobretudo como a amiga, a companheira generosa de atividades intelectuais e a interlocutora de um diálogo sem fim pelos meandros do comparatismo que lhe rendo minha mais sincera homenagem neste momento, com a certeza de que suas marcas foram impressas para sempre nas trilhas da disciplina.

E, como uma simples amostragem da escrita de Tania Carvalhal, selecionamos a seguir um de seus textos, extraído de $O$ próprio e o alheio: ensaios de literatura comparada, em que ela tece instigantes considerações sobre a "intertextualidade", conceito que ela mesma considera "básico para a atuação comparatista”. Passemos, então, à sua voz nesse estudo lapidar sobre o assunto e que porta, à maneira de Edward Said, o título de "Intertextualidade: a migração de um conceito". 